\title{
Reconsidering the Dynamic Interaction between Real Wages and Macroeconomic Activity
}

\author{
Mamadou Bobo Diallo \\ The New School for Social Research \\ New York, USA \\ E-mail: bobo.diallo@gmail.com \\ Peter Flaschel \\ Bielefeld University \\ Bielefeld, Germany \\ E-mail:pflaschel@wiwi.uni-bielefeld.de \\ Hans-Martin Krolzig \\ Kent University \\ Canterbury, UK \\ E-mail: hm.krolzig@googlemail.com \\ Christian R. Proaño (Corresponding author) \\ The New School for Social Research \\ New York, USA \\ E-mail: christian.proano@gmail.com
}

Received: September 10, $2010 \quad$ Accepted: August 12, $2010 \quad$ doi:10.5430/rwe.v2n1p77

\begin{abstract}
In this paper we investigate the role and the feedback structure of income distribution in the macro-dynamics of the U.S. economy after World War II. Among other things we analyze both theoretically and empirically the influence of job insiders on wage determination. Furthermore, by means of system GMM estimation we find empirical evidence of a negative dependence of the goods market dynamics on the development of functional income distribution in the U.S. economy.
\end{abstract}

Keywords: Distributive Cycles, Macroeconomic Dynamics, Labor Markets

\section{Introduction}

One central issue in the analysis of the income distribution conflict in capitalist economies is the question whether an increase in the real wage leads to a rise (via consumption increases) or to a decline (via lower investment) in the level of overall economic activity, or in other words, whether the economy is primarily wage-led or profit-led.

Proponents of the wage-led hypothesis often use measures of realized consumption and realized investment in order to find out whether consumption responds stronger (positively) than investment (negatively), in which case they would call the observed situation wage-led. But normally planned domestic consumption and investment (and their reaction to wage increases) do differ from their actual, realized levels due to the interplay of aggregate demand and supply as well as through the simultaneous influence of other macroeconomic variables such as the real interest or the real exchange rate, on the one hand, as well as the expectations of future developments, on the other hand, which may difficult significantly a clear-cut classification of the economy between a wage- or a profit-led categories. 
Recent empirical investigations by Hein and Vogel (2008), Stockhammer, Onaran and Ederer (2009) and others seem to suggest that aggregate demand tends to rise hand in hand with real wage increases, i.e., that goods market dynamics is actually wage-led, contradicting previous findings by Bowles and Boyer (1995) and Gordon (1995). However, Flaschel, Kauermann and Teuber (2008) have shown that not only the long-run distributive cycles in the U.S. economy over the past fifty years, but also that the short-run distributive cycles have been negatively correlated with the development of the wage share. Additionally, Proaño, Flaschel, Ernst and Semmler (2006), Franke, Flaschel and Proaño (2006) and Flaschel, Tavani, Taylor and Teuber (2007) have recently delivered some theoretical reasons as well as empirical measurements which seem to support a negative dependence, not of planned aggregate demand (which cannot be actually observed and estimated), but of the growth rate of economic activity with respect to the wage share in national income.

In this paper we intend to contribute to the academic debate by investigating further the interaction of distributive and business cycles at both the theoretical and empirical level for the U.S. economy. For this purpose we set up a medium-scale semi-structural macroeconomic model which incorporates explicitly the role of income distribution for the dynamics of aggregate demand and wage- as well as price inflation. As we will show, the wage-led hypothesis does not seem to be concordant even at the business cycle frequency in the U.S. economy, on the one hand, as well as with the empirical evidence concerning the nature of the wage-price spiral and their joint implication concerning stability on the other hand.

The remainder of this paper is organized as follows: In the next section we deliver some theoretical considerations on the wage-led/profit-led debate as well as empirical stylized facts on long- and short-run distributive and business cycles in the US economy. In section 3 we discuss the theoretical framework, with a special focus on the distributive cycle implied by it. Section 4 relates to the empirical estimation and discussion of the model. Section 5 draws some concluding remarks from this study.

\section{Theoretical Considerations, Demand Measurement Problems and Some Stylized Facts}

Based on the work by Rowthorn (1982), Dutt (1984) and Bhaduri and Marglin (1990), a large number of studies have investigated at both the theoretical and empirical level the issue whether the economy is primarily wage-led or profit-led.

In short, the core of the wage-led profit-led debate, and therefore of the income distribution conflict between the different factors of production, relies on the question whether the negative effect of a real wage increase on aggregate investment (and in an open economy, also on net exports) predominates the positive effect of rise in the real wage on aggregate consumption. In the prominent Bhaduri and Marglin (1990) model, long-run growth may be either "wage-led" or "profit-led", depending on the actual parameter values in the savings and investment functions. The outcome of the income distribution conflict, thus, is not ad initio and universally given, but rather depends on the concrete characteristics of the different economies.

As previously stated, a large number of empirical work has addressed this issue (Note 1). In one of the most influential papers, Bowles and Boyer (1995) estimate single-equations of aggregate consumption, investment and net exports for major industrialized countries, finding the domestic sectors in France, Germany, Japan, the U.K. and the U.S. as wage-led. However, when incorporating the effects of income distribution on the net exports, France, Germany and Japan become profit-led, while the U.K. and the U.S. remain wage-led economies. Hein and Vogel (2008) follow the same single-equation methodology, taking however into account the non-stationarity properties of the aggregate time series for consumption, investment, etc. Contradicting Bowles and Boyer (1995) and other previous studies, they find evidence for growth in France, Germany, the U.K. and the U.S. as being wage-led, even when taking into account international trade effects. They conclude that while small open economies might be profit led when international trade effects are taken into account, large, relatively closed economies are more likely to be wage-led. Hein and Vogel (2008), however, point out that their results (as also in the majority of related studies) were obtained using single-equation techniques, being the overall effect of income distribution simply the sum of the (independently) estimated coefficients. In a joint estimation of consumption, investment and net exports equations which would take into account the interaction of these components, the estimated coefficients might turn out to be of a different dimension.

In our view, however, these and the large majority of the existent empirical studies on the wage-led/profit-led debate oversee a central point, namely the discrepancy between aggregate demand and the realized (and observable) components of aggregate output. Going back to Keynes' (1936) acceptance of the first classical postulate in his General Theory, the simple example illustrated in Figure 1 may deliver some insight. On the one hand we have a supply curve (AS-curve) that is positively sloped, since marginal costs increase with economic activity. On the other hand we have a demand curve (AD-curve) that is negatively sloped due to its textbook IS-LM foundation. 
$<$ Figure 1 about here $>$

If we assume, following Keynes, that real wages are negatively correlated with economic activity - due to the supply schedule of firms - and if we assume that aggregate goods demand is wage-led as stressed for example by Stockhammer et al. (2009), the equality between goods demand and supply (the goods market equilibrium outcome in the AS-AD model) will always determine that only a negative correlation between economic activity (the output level) and the real wage can be observed, since only the intersection between demand and supply (which always moves along the supply curve) is actually observable. So even if goods demand was wage-led, the reaction of realized output to a real wage increase would suggest a profit-led economic activity. As illustrated in Figure 1, nominal wage increases shift the demand curve to the right implying higher activity. But they also shift the AS curve, namely to the left (or up). Since the shift of the AD curve is quite likely to be of smaller dimension than the AS-curve shift (as illustrated exemplarily in Figure 1) given the counteracting reactions of the different aggregate demand components to a real wage increase, a net reduction of the output level (with a de facto increase in the real wage) is observable as the final outcome (Note 2). This gives the reason why in our work we mainly focus on the implications of real wage changes for economic activity growth, and not in finding out what is in fact happening behind this scenario in the minds of the individual agents acting on the market for goods.

The evidence for a strictly negative relationship between real wages and economic activity, explicitly accepted by Keynes (1936), has however not been supported by the data, and is only with complicated model constructions now rationalized by neoclassical authors, see Sargent (1987) for example. Yet, Keynes may nevertheless have felt that the opposite, that wages are positively correlated with economic activity, may be politically desirable, but even less realistic than the Classical postulate $\mathrm{Nr}$. I.

Following Keynes' intuition to a certain degree, we will postulate in this paper a semi-reduced equation for goods market behavior where the growth rate of the capacity utilization rate (not its level) depends negatively on the real wage (and the real rate of interest and the level of this utilization rate as in standard AD-AS approaches of the literature). We would call such a situation a goods market that is profit-led and we will provide empirical support for the U.S. economy of this and not for the opposite.

The next graphs might deliver some further motivation for our analysis and position in the wage-led/profit-led debate. On the hand figure 2 shows the decomposition obtained through penalized splines of U.S. time series of the wage share and the employment rate in long-phase and short-phase (business cycle) components (Note 3). As it can be clearly observed, the long phase Goodwinian wage share/employment rate cycle describes by and large a pronounced counterclockwise orientation, showing that the long-phase dynamics in the labor markets are negatively correlated with the wage share in the U.S. economy.

$<$ Figure 2 about here $>$

But this correlation is not only present in the long term: For instance, Figure 3 shows the single short run distributive cycles previously depicted jointly in the lower-right panel of figure 2. Having again the employment rate on the y-axis and the wage share on the $\mathrm{x}$-axis, in five from six cycles a clockwise orientation as in the long phase cycle can be observed. The single phase diagrams of the wage share / employment rate business cycles around the long cycle shown in figure 3 have by and large the same clockwise orientation as the long phase cycle depicted in the lower-left panel of figure 2 .

\section{$<$ Figure 3 about here $>$}

In the next sections we will develop a theoretical model which will allow us to analyze the interplay between income distribution and short-run macroeconomic activity. We will get for the adjustment of the real wage from our formulation of the wage-price spiral that its growth rate depends positively on labor market activity (through money wage growth) and negatively on goods market activity (through price level growth). Depending on which of these effects is the stronger one, we get an overall positive dependence if the labor market is dominant (a situation which we will call labor market led) and a negative dependence in the opposite case of a goods market led wage price spiral.

Our empirical investigations will support the labor market led situation which thus gives a positive link from economic activity to (the growth rate of) real wages, but one that does not come from goods demand, but from wage negotiations and the price setting behavior of firms. Would a labor market led wage - price spiral situation be coupled with a wage led goods market dynamics we would have two positive feedback effects between activity levels and real wages and thus would get explosiveness (maybe existing at the times when the Nixon administration exercised a wage price stop). Our finding - among others - will however be that, on an average, real wage growth is labor-market led, but real activity growth profit-led and therefore providing a check to further real wage increases, implying stable cyclical adjustment 
processes in general. This may be understood as a weak form of the working of Keynes' (1936) Classical postulate Nr. I in an environment where the money wage dominates the wage price spiral (at least in an upward direction).

Our empirical analysis will support the theoretical intuition that real wage growth is actually labor-market led, but not due to the positive pressure from goods demand, but instead due to the positive influence generated coming from wage negotiations and the price setting behavior of firms. This result, coupled with the empirical evidence suggesting that real activity growth is profit-led, will therefore imply stable cyclical adjustment processes in general. This may be understood as a weak form of the working of Keynes' (1936) Classical postulate Nr. I in an environment where the money wage dominates the wage price spiral (at least in an upward direction). Would a labor market led wage - price spiral situation be coupled with a wage-led goods market dynamics, we would have two positive feedback effects between activity levels and real wages and thus would get explosiveness if the reaction of economic policy to these developments is too passive (see Proaño, Flaschel, Krolzig and Diallo (2010) for an analysis of the role of monetary policy in such situations under wage- and profit-led demand regimes).

\section{An Empirical Reformulation of Disequilibrium Wage-Price and Quantity Dynamics}

In this section we reconsider the Keynesian $\mathrm{D}$ (isequilibrium)AS-AD model was first introduced and investigated in Chen, Chiarella, Flaschel and Semmler (2006). This type of model questions the usual way of thinking in terms of an AS and an $\mathrm{AD}$ curve, whether static or dynamic, since its interpret its building blocks as providing equations for price and for quantity dynamics where in particular the latter represents an interaction of supply and demand and thus not an AD curve as it is customarily believed. Here we just separate quantity from wage and price dynamics in the description of the model rather than AS vs. AD as it was still the case in the previously mentioned work. We in addition formulate our dynamics price -quantity model in such a way that it can be reduced easily to smaller dimensional dynamical system which stability conditions can be investigated analytically. for a variety of stability conclusions.

\subsection{The wage-price module}

The core of our earlier theoretical framework, which allowed for non-clearing labor and goods markets and therefore for under- or over- utilized labor as well as and capital, is the modeling of the wage-price dynamics, which are specified through two separate Phillips Curves, each one led by its own measure of demand pressure (or capacity bottleneck) (Note 4). The approach of estimating separate wage and price Phillips curves is not altogether new, however: Barro (1994) for example observes that Keynesian macroeconomics is (or should be) based on imperfectly flexible wages as well as prices and thus on the consideration of wage as well as price Phillips Curves. Furthermore, Fair (2000) criticizes the low accuracy of reduced form price equations, and in the same study estimates two separate wage and price equations for the United States, nevertheless using a single demand pressure term, the NAIRU gap.

On the contrary, by modeling wage and price dynamics separately from each other, each one determined by their own measures of demand and cost pressures in the market for labor and for goods, respectively, we are able to circumvent the identification problem pointed out by Sims (1987) for the estimation of separate wage and price equations with the same explanatory variables. By these means, we can analyze the dynamics of the real wages in the economy and identify oppositely acting effects as they might result from different labor and goods markets developments. Indeed, we believe that a Keynesian model of aggregate demand fluctuations should (independently of whether justification can be found for this in Keynes' General Theory) allow for under- (or over-)utilized labor as well as capital and gradual wage as well as price adjustments in order to be general enough from the descriptive point of view.

The structural form of the wage-price module of our framework is given by (Note 5):

$$
\begin{aligned}
& \hat{w}=\beta_{w e}(e-\bar{e})+\beta_{w u}\left(u^{w}-\bar{u}^{w}\right)-\beta_{w v} \ln \left(v / v_{o}\right)+\kappa_{w} \hat{p}+\left(1-\kappa_{w}\right) \pi^{c} \\
& \hat{p}=\beta_{p u}\left(u^{c}-\bar{u}^{c}\right)+\beta_{p v} \ln \left(v / v_{o}\right)+\kappa_{p} \hat{w}+\left(1-\kappa_{p}\right) \pi^{c} \\
& \dot{\pi}^{c}=\beta_{\pi^{c}}\left(\hat{p}-\pi^{c}\right)
\end{aligned}
$$

We denote in the above equations by $e-\bar{e}$ the employment gap on the external labor market and by $u^{w}-\bar{u}^{w}$ the excess utilization of the workforce employed by firms. In a similar way, we have that $u^{c}-\bar{u}^{c}$ measures the excess utilization of the capital stock. Demand pressure on the labor market is therefore measured with respect to outsiders and insiders, while there is only one measure as far as the utilization of the capital stock is concerned (Note 6). The demand pressure terms in both the wage and price Phillips Curves are augmented by two additional terms: first, by the log of the wage share $v$ or real unit labor costs, the error correction term discussed in Blanchard and Katz (1999, p.71). The second additional term is a weighted average of corresponding expected cost-pressure terms, assumed to be perfect or 
model-consistent with respect to forward looking short-term wage and price inflation rates $\hat{w}$ and $\hat{p}$ which interact with each other in a cross-over fashion, and a backward looking measure of the prevailing inflationary climate of the economy, symbolized by $\pi^{c}$ (Note 7). Indeed, while the agents in our model have myopic perfect foresight with respect to future inflation rates, there is no reason to assume that they also act myopically with respect to the past, "forgetting" whole sequences of fully observable and highly informational values of past inflation.

The microfoundations of our wage Phillips curve are of the same type as in Blanchard and Katz (1999) (see also Flaschel and Krolzig (2006)), which can be reformulated as expressed in eqs. (1) and (2) with the employment gaps $e-\bar{e}, u^{w}-\bar{u}^{w}$ in place of the usually employed single measure, the output gap. We use two measures of demand pressure on the labor market, the external employment rate gap and the utilization gap within firms. Using a physical analogy they can be regarded as forming some sort of capillary system when these two pressure terms are coupled with some sort of Okun's law.

Concerning the price Phillips curve, a similar micro-procedure can be applied, based on desired markups of firms. Along these lines one in particular gets an economic motivation for the inclusion of (indeed the logarithm of) the real wage (or wage share) with negative sign in the wage PC and with positive sign in the price PC, without any need for loglinear approximations as in the New Keynesian approaches. Our wage-price module is thus consistent with standard models of unemployment based on efficiency wages, matching and competitive wage determination, as well as markup pricing and can be considered as an interesting alternative to the - theoretically rarely discussed and empirically questionable purely forward-looking New Keynesian form of staggered wage and price dynamics that we have discussed in section 1 . Moreover, the wage price mechanism can also be interpreted in terms of a Postkeynesian approach as formulated in Barbosa-Filho and Taylor (2006).

Note again that we have assumed model-consistent expectations with respect to short-run wage and price inflation, incorporated into our Phillips curves in a cross-over manner, with perfectly foreseen price inflation in the wage Phillips Curve and wage inflation in the price - Phillips curve, appearing in a weighted average form relative to our inflationary climate expression in both the wage and the price Phillips curve.

\subsection{The quantity module}

The quantity module of our model is formed by a reduced form goods market dynamics and a link to the labor market by an appropriate formulation of Okun's law.

The above model of an advanced wage-price spiral is considered in this paper against the background of a fixed proportions technology, characterized by (Note 8)

$y^{p}=Y^{p} / K=$ const,$\quad z=Y / L^{d}=$ const $, u^{c}=Y / Y^{p}, \quad u^{w}=L^{d} / L^{w}, \quad e=L^{w} / L$.

Potential output $Y^{p}$ is here compared with actual output $Y$, which is in this model demand determined. The ratio $u^{c}$ is therefore the rate of capacity utilization of firms. Firms employ a workforce of $L^{w}$ workers who are employed according to actual output and thus have to supply $L^{d}=Y / z$ hours of work. Their rate of utilization is therefore given by $u^{w}$. The rate of employment on the external labor market is finally defined by $e$ and has already been contrasted in its implications for wage inflation with the rate $u^{w}$ in the WPC we have introduced above.

With respect to the goods markets dynamics, we model these by means of a law of motion of the type of a dynamic IS-equation (see also Rudebusch and Svensson (1999) in this regard) here represented by the growth rate of the capacity utilization rate of firms (Note 9):

$\hat{u}^{c}=-\beta_{u u}\left(u^{c}-\bar{u}^{c}\right)-\beta_{u i}\left((i-\hat{p})-\left(i_{o}-\pi_{o}\right)\right) \pm \beta_{u v}\left(v-v_{o}\right)$

The reduced form (4) has three important characteristics; (i) it reflects the dependence of output changes on aggregate income and thus on the rate of capacity utilization by assuming a negative, i.e., stable (partial) dynamic multiplier relationship in this respect, (ii) it shows the joint dependence of consumption and investment on the real wage / wage share (which in the aggregate may in principle allow for positive or negative signs before the parameter $\beta_{u v}$, depending on whether consumption or investment is more responsive to real wage changes / wage share changes) and (iii) it shows finally the negative influence of the real rate of interest (its deviation from its steady state level) on the evolution of economic activity.

Concerning the labor market dynamics and their link to the goods market dynamics, we assume a more detailed form of the simple empirical relationship introduced in Okun (1970) as the link between the rate of capacity utilization and the employment rate, namely 


$$
\hat{e}=\beta_{e u}\left(u^{w}-\bar{u}^{w}\right), \quad u^{w}=\frac{L^{d}}{L^{w}}=\frac{Y^{p}}{K} \frac{L^{d}}{Y} \frac{K}{L} \frac{Y}{Y^{p}} \frac{L}{L^{w}}=\frac{y^{p}}{z l_{o}} \frac{u^{c}}{e}
$$

This law of motion states that the growth rate of the employment rate is reacting positively to the deviation of the utilization rate $u^{w}$ - the ratio of $L^{d}$ (employment in hours) to the workforce $L^{w}$ of firms - from its normal level $\bar{u}^{w}$. The utilization rate $u^{w}$ depends in turn - as shown in (5) - on the rate of capacity utilization $u^{c}$ and the employment rate $e$ by definition, if a fixed proportions technology is assumed: $y^{p}=Y^{p} / K=$ const, $z=Y / L^{d}=$ const, $L^{d}$ the employment of the workforce of firms (in hours), and on the ratio of labor supply to the capital stock $L / K$ which is here considered a given magnitude $l_{o}$ (thereby ignoring the growth aspects behind the model) (Note 10). The essential parameter here is of course the parameter $\beta_{\text {eu }}$, which characterizes the speed of the hiring and firing process of the firms of the considered economy.

The above three laws of motion therefore reformulate in a dynamic form the static AD- and AS-curves and the interaction they give rise on the quantity side of the economy.

\subsection{The policy module}

Concerning monetary policy, we model the nominal interest rate as being determined by a simple Taylor rule without interest rate smoothing (see for comparison Svensson (1999)). Hereby we assume the target rate of the monetary authorities as being determined by:

$i=i_{o}+\alpha_{i p}(\hat{p}-\bar{\pi})+\alpha_{i u}\left(u^{c}-\bar{u}^{c}\right)+\alpha_{i v}\left(v-v_{o}\right)$

The target rate of the central bank $i$ is thus made dependent on the steady state real rate of interest $i_{o}-\pi_{o}$, and is as usual dependent on the inflation gap and the capacity utilization gap (as a measure of the output gap), yet augmented here by a further gap impact, the current wage share gap (Note 11). For the time being we assume that there is no interest rate smoothing with respect to the interest target of the central bank, which therefore immediately set its target rate at each moment in time. This allows to insert the interest rate policy rule directly into the law of motion characterizing the market for goods and thus saves one law of motion in the investigation of the economy.

We note that the steady state of the dynamics, due to its specific formulation, can be supplied exogenously (Note 12):

$u_{o}^{c}=\bar{u}^{c}, e_{o}=\bar{e}, u_{o}^{w}=\bar{u}^{w}, v_{o}=$ const., $\pi_{o}^{c}=\hat{p}_{o}=\hat{w}_{o}=0, i_{o}=(i-\hat{p})_{o}$.

This shows that the model has been constructed around a specific steady state position, the stability of which will be the focus of interest in the next section.

\subsection{The integrated dynamics}

Taken together the model of this section consists of the following four laws of motion for capacity utilization $u^{c}$, the goods market dynamics, for the employment rate $e$, Okun's law, for the wage share $v$, describing the real wage channel (to be derived in the next section), and for the inflationary climate expression $\pi^{c}$ (to be supplemented by a reduced form PPC also derived in the next section) and with reduced form expressions by assumption concerning the goods and the labor market dynamics) (Note 13). The intensive form dynamics thus read (first the quantity side, then the price module):

$$
\begin{aligned}
\hat{u}^{c}= & -\beta_{u u}\left(u^{c}-\bar{u}^{c}\right)-\beta_{u i}\left((i-\hat{p})-(i-\hat{p})_{o}\right) \pm \beta_{u v}\left(v-v_{o}\right) \\
\dot{e}= & \beta_{e u} \frac{y^{p}}{z l_{o}}\left(u^{c}-\bar{u}^{c} \frac{e}{e_{o}}\right), y^{p}, z, l_{o} \text { given } \\
\hat{v}= & \hat{w}-\hat{p} \\
= & \kappa\left[\left(1-\kappa_{p}\right)\left(\beta_{w e}(e-\bar{e})+\beta_{w u}\left(\frac{y^{p}}{z l_{o}} \frac{u^{c}}{e}-\bar{u}^{w}\right)-\beta_{w v} \ln \left(v / v_{o}\right)\right)\right. \\
& \left.-\left(1-\kappa_{w}\right)\left(\beta_{p u}\left(u^{c}-\bar{u}^{c}\right)+\beta_{p v} \ln \left(v / v_{o}\right)\right)\right] \\
\dot{\pi}^{c}= & \beta_{\pi^{c}}\left(\hat{p}-\pi^{c}\right)
\end{aligned}
$$

with the supplementary equations $\left(\kappa=\frac{1}{1-\kappa w \kappa p}\right)$ : 


$$
\begin{aligned}
i-\hat{p}= & (i-\hat{p})_{o}+\alpha_{i p}(\hat{p}-\bar{\pi})+\alpha_{i u}\left(u^{c}-\bar{u}^{c}\right)+\alpha_{i v}\left(v-v_{o}\right) \\
\hat{p}-\pi^{c}= & \kappa\left[\beta_{p u}\left(u^{c}-\bar{u}^{c}\right)+\beta_{p v} \ln \left(v / v_{o}\right)\right. \\
& \left.+\kappa_{p}\left(\beta_{w e}(e-\bar{e})+\beta_{w u}\left(u^{w}-\bar{u}^{w}\right)-\beta_{w v} \ln \left(v / v_{o}\right)\right)\right]
\end{aligned}
$$

to be inserted into these laws of motion in order to get an autonomous system of differential equations (in the empirical estimation of the model we will add interest rate smoothing to the considered dynamics, since this improves the estimates). Here however, we can immediately insert the Taylor rule into the goods market dynamics and obtain by and large the result that the negative feedbacks in this law of motion will be enhanced thereby, showing again that the sign in front of the wage share in the law of motion for $u^{c}$ can depend on much more than just the aggregate demand function of the economy. We may consider the state variables $e, \pi^{c}$ as slow variables and even suppress their motion by assuming $\beta_{e u}=0, \beta_{\pi^{c}}=0$ and then get only the interaction of capacity utilization with income distribution, augmented by the impact of monetary policy working through the real rate of interest rate channel in interaction with the reduced form price Phillips curve. In the next section we will even suppress this real interest rate channel and thus study the distributive cycle in a Keynesian setup by itself.

Note finally that we have tailored the Taylor rule in view of the central feedback channels that characterize this economic structure, in particular for the case where the economy is wage- as well as labor-market-led, see the next section, and thus unstable from the perspective of this partial real wage feedback chain. This exemplifies that an understanding of the important feedback channels of the private sector is essential for a proper formulation of interest rate policy rules.

\section{The Distributive Cycle of the Model}

The across-markets or reduced-form PC's of the Wage PC and the Price PC (1), (2) are given by (with $\kappa=1 /\left(1-\kappa_{w} \kappa_{p}\right)$ ) (Note 14):

$$
\begin{aligned}
& \hat{w}=\kappa\left[\beta_{w e}(e-\bar{e})+\beta_{w u} \chi\left(u^{c} / e-\bar{u}^{c} / e_{o}\right)-\beta_{w v} \ln \left(v / v_{o}\right)+\kappa_{w}\left(\beta_{p u}\left(u^{c}-\bar{u}^{c}\right)+\beta_{p v} \ln \left(v / v_{o}\right)\right)\right]+\pi^{c}, \\
& \hat{p}=\kappa\left[\beta_{p u}\left(u^{c}-\bar{u}^{c}\right)+\beta_{p v} \ln \left(v / v_{o}\right)+\kappa_{p}\left(\beta_{w e}(e-\bar{e})+\beta_{w u} \chi\left(u^{c} / e-\bar{u}^{c} / e_{o}\right)-\beta_{w v} \ln \left(v / v_{o}\right)\right)\right]+\pi^{c},
\end{aligned}
$$

with $\chi=y^{p} /\left(y l_{o}\right)$ inflation pass-through terms behind the $\kappa_{w}, \kappa_{p}$-parameters. These reduced form PC's represent a considerable generalization of the conventional view of a single-market price PC with only one measure of demand pressure, namely the one in the labor market. They are easily derived when account is taken of the fact that the equations (1),(2) can easily be rewritten as a system of two linear equations in the variables $\hat{w}-\pi^{c}, \hat{p}-\pi^{c}$ and solved through the usual inversion of the 2 by 2 system-matrix that is thereby obtained.

Note that for this version of the wage-price spiral, the inflationary climate variable does not matter for the evolution of the real wage $\omega=w / p,-$ or the wage share $v=\omega / z$ if labor productivity is taken into account. The law of motion for the wage share $v$ is obtained by deducing the second from the first of the preceding equations (whereby $\pi^{c}$ is canceled) and is given by:

$$
\begin{aligned}
\hat{v}= & \kappa\left[\left(1-\kappa_{p}\right)\left(\beta_{w e}(e-\bar{e})+\beta_{w u} \chi\left(u^{c} / e-\bar{u}^{c} / e_{o}\right)-\beta_{w v} \ln \left(v / v_{o}\right)\right)\right. \\
& \left.-\left(1-\kappa_{w}\right)\left(\beta_{p u}\left(u^{c}-\bar{u}^{c}\right)+\beta_{p v} \ln \left(v / v_{o}\right)\right)\right] .
\end{aligned}
$$

This provides equation (9) of our model's equations. Equation (11) shows the ambiguity of the stabilizing role of the real wage channel, already discussed by Rose (1967) which arises - despite the incorporation of specific measures of demand and cost pressure on both the labor and the goods markets - if the dynamics of the employment rate and the workforce utilization are linked to the fluctuations of the firms' capacity utilization rate via Okun's law. Indeed, as sketched in Figure 4, a real wage increase can act, taken by itself, in a stabilizing or destabilizing manner, depending among other things on whether the dynamics of the capacity utilization rate depend positively or negatively on the real wage (i.e. on whether consumption reacts more strongly to real wage changes than investment or vice versa) and whether price flexibility is greater than nominal wage flexibility with respect to its own demand pressure measure. All parameters shown in the first part of equation (11) thus contribute to stability if aggregate demand is profit-led, i.e., decreases when the real wage is increasing, while the ones after the minus sign contribute to instability in this case (the opposite applies when aggregate demand is wage-led).

$<$ Figure 4 about here $>$ 
Augmented by the quantity side without link to the interest rate channel yet and also without link to the external labor market (by setting $\alpha_{u i}, \beta_{e u}=0, e=e_{o}$ ) for the time being, we obtain:

$$
\begin{aligned}
\hat{v}= & \kappa\left[\left(1-\kappa_{p}\right)\left(\beta_{w u} \chi\left(\frac{u^{c}-\bar{u}^{c}}{e_{o}}\right)-\beta_{w v} \ln \left(v / v_{o}\right)\right)\right. \\
& \left.-\left(1-\kappa_{w}\right)\left(\beta_{p u}\left(u^{c}-\bar{u}^{c}\right)+\beta_{p v} \ln \left(v / v_{o}\right)\right)\right] \\
\hat{u}^{c}= & -\beta_{u u}\left(u^{c}-\bar{u}^{c}\right) \pm \beta_{u v}\left(v-v_{o}\right)
\end{aligned}
$$

and thus an autonomous system of two laws of motion in the real state variables $v$, the wage share in national income, and the rate of capacity utilization of the capital stock, $u^{c}$. This is the distributive subdynamics of the model as it is also formulated in Barbosa-Filho and Taylor (2006) with maybe a different interpretation of the building blocks of this Goodwin (1967) growth cycle model type.

The Jacobian matrix $J$ of the dynamical system at the interior steady state is characterized by:

$$
\begin{aligned}
J & =\left(\begin{array}{cc}
-\kappa\left[\left(1-\kappa_{p}\right) \beta_{w v}+\left(1-\kappa_{w}\right) \beta_{p v}\right] & \kappa\left[\left(1-\kappa_{p}\right) \frac{\beta_{w u} \chi}{e_{o}}-\left(1-\kappa_{w}\right) \beta_{p u}\right] v_{o} \\
\pm \beta_{u v} u_{o}^{c} & -\beta_{u u} u_{o}^{c}
\end{array}\right) \\
& =\left(\begin{array}{ll}
- & \pm \\
\pm & -
\end{array}\right)
\end{aligned}
$$

As it can be easily observed, the above Jacobian matrix allows for four different cases, indeed the four cases illustrated in Figure 4. These four different scenarios can be jointly summarized as in Table 1. As illustrated there, there exist two cases where the Rose (1967) real wage channel operates in a stabilizing manner: In the first case, aggregate quantity growth characterizing the goods market (approximated in our analysis by the capacity utilization rate) depend negatively on the real wage, which can be denoted in a closed economy as ' a profit-led goods market' (Note 15) - and the dynamics of the real wage are led primarily by the nominal wage dynamics and therefore by the developments in the labor market. In this case labor market led real wage increases receive a check through the implied negative effect on goods markets activity levels. In the second case, quantitative growth depends positively on the real wage, a wage-led goods market, and the price level dynamics, and therefore the goods markets, primarily determines the behavior of the real wages (Note 16).

<Table 1 about here $>$

The Jacobians in the diagonal of Table 1 will be stable if and only if the following inequality applies:

$\frac{\beta_{u u}}{\beta_{u v}}>\frac{\left(1-\kappa_{p}\right) \frac{\beta_{w u} \chi}{e_{o}}-\left(1-\kappa_{w}\right) \beta_{p u} v_{o}}{\left(1-\kappa_{p}\right) \beta_{w v}+\left(1-\kappa_{w}\right) \beta_{p v}}$

i.e., if the capacity utilization effect in the law of motion for the rate of capacity utilization is sufficiently large. Stability in the case of the combinations wage- and labor market-led as well as profit- and goods market-led depend thus on the strength of the feedback of capacity utilization on its own rate of growth. The questions when and where this is the case can of course only be answered through empirical investigations.

Since the signs in the Jacobians also hold true for all points in the positive orthant of $\mathfrak{R}^{2}$ (which cannot be left by the trajectories that start in it, since its boundary is an invariant set of the dynamics) the 2 cyclical patterns also hold true in the large and - if made convergent by adding again the negative diagonal entries - are globally convergent by virtue of Olech's theorem. In the case of the other two figures - the saddles - the unstable separatrices directed towards the boundary of the economic phase space are approaching the axes of the positive orthant, but not cutting them (or are converging to the origin of the phase space or to infinity). And in the cases where the dynamics switches by parameter changes to one of the other regimes shown in figure 3, this will only occur in general (up to flukes) in the way shown by the black arrows in this figure, but not by a simultaneous change of two market characteristics at the same time.

The considered 2D subdynamics of the full 4D dynamics can be considered to represent an insider-approach to the distributive cycle of Goodwin (1967). It has added stabilizing dual dynamics (the entries in the diagonal of the matrix J) which represent the Keynesian dynamic multiplier process and the Blanchard and Katz (1999) wage negotiations error 
correction terms. And it allows for four possible situations concerning wage and price flexibilities and the relationship between the real wage and economic activity (a strictly negative one according to Keynes (1936)), as they were already in principle considered in the seminal paper by Rose (1967) and as they are shown in table 2 and figure 3 . It is possible to add the role of outsiders to the dynamics, allowing for a fluctuating employment rate $e$ by assuming $\beta_{e u}>0$, which however does not alter significantly the principles governing these distributive dynamics, but which adds of course a third law of motion to them. The important thing in these dynamics is that we have - in place of Keynes (1936) strictly negative correlation between the real wage and economic activity - now two interacting growth laws instead of one static relationship as in his case, a situation which nevertheless allows to share his view on negative real wage / economic activity relationships to a certain degree if the goods market is profit-led and the wage-price dynamics labor market-led. We believe that it is a great advantage to have at our disposal a pair of dynamic relationships in place of Keynes' (1936) single static one, in order to investigate on this enlarged basis the type of the real wage channel empirically and - on this basis - the role of fiscal and monetary policy.

We next show, in Figure 5, the local phase portraits of the four considered cases in the same order as the matrices shown in Table 1, under the additional assumption that the diagonal terms in these matrices are still zero (which makes the isoclines all vertical or horizontal and the Jacobian in the diagonal of Table 1 unstable). The qualitative features are not changed by this special assumption, if the multiplier process is sufficiently weak, but the slopes of the isoclines are then no longer as extreme as in the limit case of zero diagonal entries.

$<$ Figure 5 about here $>$

Recall that on the left hand side economic activity is always wage led, and profit led on the right hand side. Real wage growth is labor market led in the top figures and goods market led in the bottom figures. The symmetric combinations wage- and labor market-led and profit- and goods market-led imply in the assumed situation saddle-point dynamics. In the first case we have the plausible dynamic features of a self-enforcing inflationary boom or a self-enforcing deflationary depression, respectively. In actual economies the first situation may be stopped by contractive monetary and fiscal policy, while the remedy in the second case may only be downward wage rigidity, formalized by way of a kinked wage Phillips curve for example, see Chiarella and Flaschel (2000) and Flaschel et al. (2007). The model structures in these case are therefore either incomplete or only temporarily at work and changing into the dynamics shown on the off-diagonal in figure 3 through appropriate parameter changes. The combination profit- and labor market-led is in the shown situation exactly equal to the Marx - Goodwin growth cycle model. It will produce convergent dynamics if the effects in the trace of the matrix $J$ are added again. The typical prediction of this situation is that the distributive cycle has a clockwise orientation (if the diagonal terms in $J$ are not too strong). In the opposite case, which combines wage with goods market led, we have the opposite orientation, i.e., an anti-clockwise one. This is due to the fact that real wage changes are dominated by price level effects and not by changes in the money wage so that we get a falling wage share in situations of high economic activity and a rising wage share in situations of low economic activity. We do not consider this a long-lasting regime, but would conclude as in Flaschel et al. (2007) that it may temporarily existed during the sequence of business cycles that have characterized for example the US economy after World War II.

Of the situations shown in figure 5 , the one bottom right seems to be the one that is the least plausible. It shows on the top-left profitability booms where prices outperform wages systematically and on the bottom-right a profitability crisis where low activity is coupled with rising real wages, since prices fall faster then wages. From a temporary perspective however all situations shown can happen, but in view of Keynes' (1936) assumption of a strictly negative relationship between real wages and economic activity in a capitalist economy, we would expect this distributive conflict constraint is characterizing capitalistic economies in the longer run and thus maybe founded on the weaker conflicting claims assumptions that underlie the situation top right in Figure 5.

\section{Econometric Analysis}

For the econometric estimation of the model we use the aggregate time series of the U.S. economy from the FRED database. The data is quarterly, seasonally adjusted and concerns the period from 1973:1 to 2008:2.

The logarithms of wages and prices are denoted $\ln \left(w_{t}\right)$ and $\ln \left(p_{t}\right)$, respectively. Their first differences (backwardly dated), i.e. the current rate of wage and price inflation, are denoted $\hat{w}_{t}$ and $\hat{p}_{t}$. The inflationary climate $\pi^{c}$ of the theoretical part of this paper is approximated here in a very simple way by a linearly declining moving average of CPI price inflation rates with linearly decreasing weights over the past twelve quarters, denoted $\pi_{t}^{12}$.

$<$ Table 2 about here $>$ 
In order to be able to identify in a structural manner the dynamics of the system and especially of the wage and price inflation (since as discussed previously, the law of motion for the real wage rate, given by equation (11), represents a reduced form expression of the two structural equations for $\hat{w}_{t}$ and $\hat{p}_{t}$ ), we estimate the following discrete time reformulation of our continuous time theoretical model (described in section 3) (Note 17):

$$
\begin{aligned}
\hat{w}_{t} & =\beta_{w e}\left(e_{t-1}-e_{o}\right)+\beta_{w u} \chi\left(\frac{u_{t-1}^{c}}{e_{t-1}}-\frac{u_{o}^{c}}{e_{o}}\right)-\beta_{w v} \ln \left(v_{t-1} / v_{o}\right)+\kappa_{w p} \hat{p}_{t} \\
& +\left(1-\kappa_{w p}\right) \pi_{t-1}^{12}+\kappa_{w z} \hat{z}_{t}+\varepsilon_{w t} \\
\hat{p}_{t} & =\beta_{p u}\left(u_{t-1}^{c}-u_{o}^{c}\right)+\beta_{p v} \ln \left(v_{t-1} / v_{o}\right)+\kappa_{p w}\left(\hat{w}_{t}-\hat{z}_{t}\right)+\left(1-\kappa_{p w}\right) \pi_{t-1}^{12}+\varepsilon_{p t} \\
u_{t}^{c} & =u_{t-1}^{c}-\beta_{u u}\left(u_{t-1}^{c}-u_{o}^{c}\right)-\beta_{u i}\left(i_{t-1}-\hat{p}_{t}\right) \pm \beta_{u v}\left(v_{t-1}-v_{o}\right)+\varepsilon_{u t} \\
\ln e_{t} & =\ln e_{t-1}+\beta_{e u} \chi\left(\frac{u_{t}^{c}}{e_{t-1}}-\frac{u_{o}^{c}}{e_{o}}\right)+\varepsilon_{e t} \\
i_{t} & =\varphi_{i} i_{t-1}+\left(1-\varphi_{i}\right) \alpha_{i p} \hat{p}_{t}+\left(1-\varphi_{i}\right) \alpha_{i u}\left(u_{t-1}^{c}-u_{o}^{c}\right)+c_{i}+\varepsilon_{i t},
\end{aligned}
$$

with $\chi=\frac{y^{p}}{z l_{l}}$ for notational simplicity and all variables with a subscript $O$ denoting sample averages (interpretable as the analogue to the steady state values in the theoretical model). The statistical error terms in each equation are represented by the respective $\varepsilon$.

In order to account for regressor endogeneity, we estimate the discrete time version of the structural model formulated above by means of instrumental variables system GMM (Generalized Method of Moments) (Note 18). The weighting matrix in the GMM objective function was chosen in order to allow the resulting GMM estimates to be robust against possible heteroskedasticity and serial correlation of an unknown form in the error terms. Concerning the instrumental variables used in this estimation, since at time $t$ only past values are contained in the information sets of the economic agents we use, besides the strictly exogenous variables, lagged values of the employment rate, the labor share (detrended by the Hodrick-Prescott Filter) and the growth rate of labor productivity. In order to test for the validity of the overidentifying restrictions, the $J$ - statistics was computed.

For starters it should be pointed out that the large majority of parameter estimates confirm previous estimates as discussed in Flaschel and Krolzig (2006) and Proaño et al. (2006). This hold particularly true for the estimated parameters in both the wage and price inflation adjustment equations, what confirms the specification of the wage-spiral discussed in this paper. However, the inclusion of job insiders' power (represented by utilization gap of the workforce employed by firms) besides the influence of the outsiders (represented by the employment gap) on the development of wage inflation delivers an interesting new insight with respect to the mentioned previous studies, namely that the influence of the former is significantly higher than that of the latter, despite the low degree of trade union organization of the U.S. economy. Besides this new insight, the estimations confirm the notion that income distribution (through the $\log$ level of wage share, or more specifically, through its log deviation from its long run trend) influence not only the dynamics of nominal wages but, through its influence also on the dynamics of price inflation, also the real wages.

\section{$<$ Table 3 about here $>$}

Looking at the dynamic IS equation represented here by the capacity utilization equation, the coefficient $\beta_{u v}$, which represents the influence of an increase in the wage share on the growth rate of capacity utilization, it is negative and statistically significant, supporting our initial presumption the goods market dynamics are profit led as proposed by the neoclassical approach.

Concerning the dynamics of the employment rate, our estimates deliver a rather low reaction coefficient of the change in the employment rate to the internal employment gap. However, due to the consistency of the parameter estimates with the corresponding values in the price inflation adjustment equation, the internal employment gap seems to be significant, i.e., important for the dynamics of the employment rate. And last but not least, our estimates of the nominal interest rate rule can be considered as in line with the great majority of empirical studies on the U.S. monetary policy, see e.g. Taylor (1999).

A quick look at the Jacobian matrix for the two dimensional dynamical system formed by equations (12) and (13) gives us the following:

$$
J=\left(\begin{array}{ll}
- & - \\
+ & -
\end{array}\right)
$$


Following Barbosa-Filho and Taylor (2006), one would say that the Distributive curve for the U.S. is positively slopped, so that there is a profit squeeze. Furthermore, we find for the U.S that the aforementioned distributive cycle is mainly driven by insiders ( $u^{w}$ effect) than the outsiders, as $\beta_{w u} \chi=0.668>\beta_{e u} \chi=0.028$ and Okun's law is almost a one to one relationship going from capacity utilization to workforce utilization $\left(u_{o}^{c} / e_{o}=1.047\right)$. As a result, the U.S. real wage adjustment could be described as procyclical or labor market-led.

\section{Concluding Remarks}

In this paper we focused on short run distributive cycles and the plausibility of wage-led regimes often discussed in the literature. Starting from the intuition which questions the very "meaningfulness" of empirical studies which investigate the wage-led/profit-led nature of economic activity, we delivered some stylized empirical facts as well as dynamic system theory which concerned the interaction of wage-price dynamics, income distribution and economic activity.

Our integrated approach to macrodynamics, which takes into account the different feedback mechanisms acting in a modern economy, allowed us to question the plausibility of a "wage-led" economy when taking into account that the real wage dynamics seem to be primarily labor markets-led. It is our view that the proper study of the macroeconomy (and its categorization into different "regimes") can only be performed not simply through partial considerations, but instead through an integrated modeling of the economy into a closed dynamical system (microfounded or not), where all relevant macroeconomic variables and their interactions are taken into account and are properly specified.

\section{References}

Barbosa-Filho, N. and Taylor, L. (2006), 'Distributive and demand cycles in the US economy - a structuralist Goodwin model', Metroeconomica 57(3), 389 - 411. doi:10.1111/j.1467-999X.2006.00250.x, http://dx.doi.org/10.1111/j.1467-999X.2006.00250.x

Barro, R. (1994), 'The aggregate supply / aggregate demand model', Eastern Economic Journal 20, 1-6.

Bhaduri, A. and Marglin, S. (1990), 'Unemployment and the real wage: the economic basis for contesting political ideologies', Cambridge Journal of Economics 14, 375 - 93.

Blanchard, O. J. and Katz, L. (1999), 'Wage dynamics: Reconciling theory and evidence', American Economic Review 89, 69-74. Papers and Proceedings of the One Hundred Eleventh Annual Meeting of the American Economic Association (May, 1999).

Bowles, S. and Boyer, R. (1995), Wages, aggregate demand and employment in an open economy: an empirical investigation, in G. Epstein and H. Gintis, eds, 'Macroeconomic Policy after the Conservative Era', Cambridge University Press, Cambridge, U.K.

Chen, P., Chiarella, C., Flaschel, P. and Semmler, W. (2006), Keynesian macrodynamics and the Phillips Curve. An estimated baseline macromodel for the U.S. economy, in C. Chiarella, P. Flaschel, R. Franke and W. Semmler, eds, 'Quantitative and Empirical Analysis of Nonlinear Dynamic Macromodels', Elsevier, Amsterdam. doi:10.1016/S0573-8555(05)77008-5, http://dx.doi.org/10.1016/S0573-8555(05)77008-5

Chen, P. and Flaschel, P. (2006), 'Measuring the interaction of wage and price Phillips Curves for the U.S. economy', Studies in Nonlinear Dynamics and Econometrics 10, 1-35. doi:10.2202/1558-3708.1255, http://dx.doi.org/10.2202/1558-3708.1255

Chiarella, C. and Flaschel, P. (2000), The Dynamics of Keynesian Monetary Growth: Macro Foundations, Cambridge University Press, Cambridge, U.K. doi:10.1017/CBO9780511492396, http://dx.doi.org/10.1017/CBO9780511492396

Chiarella, C., Flaschel, P. and Franke, R. (2005), Foundations for a Disequilibrium Theory of the Business Cycle. Qualitative Analysis and Quantitative Assesment, Cambridge University Press, Cambridge, U.K. doi:10.1017/CBO9780511492402, http://dx.doi.org/10.1017/CBO9780511492402

Dutt, A. K. (1984), 'Stagnation, income distribution and monopoly power', Cambridge Journal of Economics 8, 25 - 40.

Fair, R. (2000), 'Testing the NAIRU model for the United States', The Review of Economics and Statistics 82, 64-71. doi:10.1162/003465300558632, http://dx.doi.org/10.1162/003465300558632

Flaschel, P., Kauermann, G. and Teuber, T. (2008), 'Long cycles in employment, inflation and real wage costs. Qualitative analysis and quantitative assesment', American Journal of Applied Sciences Special Issue, 69 - 77.

Flaschel, P. and Krolzig, H.-M. (2006), Wage-price Phillips Curves and macroeconomic stability. Basic structural form, estimation and analysis, in C. Chiarella, P. Flaschel, R. Franke and W. Semmler, eds, 'Quantitative and Empirical 
Analysis of Nonlinear Dynamic Macromodels', Elsevier, Amsterdam. doi:10.1016/S0573-8555(05)77002-4, http://dx.doi.org/10.1016/S0573-8555(05)77002-4

Flaschel, P., Tavani, D., Taylor, L. and Teuber, T. (2007), A structuralist model of the wage-price spiral with non-linear demand pressure terms, Working paper, Schwarz Center for Economic Policy Analysis. New School University, New York.

Franke, R., Flaschel, P. and Proaño, C. R. (2006), 'Wage-price dynamics and income distribution in a semi-structural Keynes-Goodwin model', Structural Change and Economic Dynamics 17(4), 452-465. doi:10.1016/j.strueco.2006.08.001, http://dx.doi.org/10.1016/j.strueco.2006.08.001

Gordon, D. (1995), Growth, distribution, and the rules of the game: social structuralist macro foundations for a democratic economic policy, in G. Epstein and H. Gintis, eds, 'Macroeconomic Policy after the Conservative Era', Cambridge University Press, Cambridge, U.K., pp. 335 - 383.

Hein, E. and Vogel, L. (2008), 'Distribution and growth reconsidered - Empirical results for six OECD countries', Cambridge Journal of Economics 32, 479 - 511. doi:10.1093/cje/bem047, http://dx.doi.org/10.1093/cje/bem047

Okun, A. M. (1970), The Political Economy of Prosperity, The Brookings Institution.

Proaño, C. R., Flaschel, P., Ernst, E. and Semmler, W. (2009), Disequilibrium macroeconomic dynamics, income distribution and wage-price Phillips Curves: Evidence from the U.S. and the Euro Area, Working Paper 4/2006, Macroeconomic Policy Institute (IMK), Düsseldorf.

Rose, H. (1967), 'On the non-linear theory of employment', Review of Economic Studies 34, 153-173. doi:10.2307/2296806, http://dx.doi.org/10.2307/2296806

Rowthorn, R. E. (1982), 'Demand, real wages, and economic growth', Studi Economici 18, 2 - 53.

Rudebusch, G. D. and Svensson, L. E. (1999), Policy rules for inflation targeting, in J. B. Taylor, ed., 'Monetary Policy Rules', The University of Chicago Press, Chicago, chapter 15.

Sims, C. (1987), 'Discussion of Olivier J. Blanchard, aggregate and individual price adjustment', BPEA 1, 117-20.

Svensson, L. E. (1999), 'Inflation targeting as a monetary policy rule', Journal of Monetary Economics 43(6790), 607654. doi:10.1016/S0304-3932(99)00007-0, http://dx.doi.org/10.1016/S0304-3932(99)00007-0

Taylor, J. B., ed. (1999), Monetary Policy Rules, Vol. 31 of Business Cycles Series, National Bureau of Economic Research, The University of Chicago Press, Chicago.

Wooldridge, J. M. (2001), 'Applications of generalized method of moments estimation', Journal of Economic Perspectives 15(4), 87-100. doi:10.1257/jep.15.4.87, http://dx.doi.org/10.1257/jep.15.4.87

\section{Notes}

Note 1. For a recent survey on the empirical literature on this topic, see Hein and Vogel (2008).

Note 2. It should be clear that this type of graphical analysis in the case of a profit-led goods demand leads also to an observational profit-led outcome.

Note 3. See Flaschel et al. (2008) for a description of this methodology.

Note 4. This model of the wage-price spiral and its coupling with an adaptively updated inflationary climate expression (representing the inertia inherent in this wage-price spiral) has a long tradition in our formulations of disequilibrium adjustment processes, see in particular Chiarella and Flaschel (2000) and Chiarella, Flaschel and Franke (2005) in this regard.

Note 5. We have stressed elsewhere, see e.g. Chen et al. (2006), the close formal correspondence of this model of a wage-price spiral with the New Keynesian model of staggered wage and price setting. Yet we have to stress here in this regard that we employ three demand pressure gaps in this spiral in place of the single one (the output gap) that is used by New Keynesian authors. Despite formal similarity the conclusions drawn from our macrodynamic model are in direct opposition to the ones of the New Keynesian macrodynamics.

Note 6. Adding an inventory gap would be a natural extension in the case of manufacturing.

Note 7. This last term is modeled by an adaptively updating mechanism that uses new information on current price inflation rates. 
Note 8. For a simple inclusion of smooth factor substitution - which makes $y^{p}$ dependent on the real wage - see Chiarella and Flaschel (2000) and also Chiarella, Flaschel and Franke (2005) for the discussion of alternative production technologies.

Note 9. Note here that the empirically observed controversy about income distribution does not play a role in the New Keynesian formulation of the goods market dynamics, due to its reliance on a single representative household (who receives all wage as well as profit income and who thus can be indifferent with respect to changing income distribution if total income remains the same).

Note 10. This assumption is justified if it is assumed that labor supply always grows in line with capital stock growth.

Note 11. All of the employed gaps are measured relative to the steady state of the model, in order to allow for an interest rate policy that is also consistent with the steady state.

Note 12. We assume for reasons of consistency: $\bar{u}^{w}=y^{p} \bar{u}^{c} /\left(z l_{o} \bar{e}\right)$.

Note 13. As the model is formulated we have no real anchor for the steady state rate of interest (via investment behavior and the rate of profit it implies in the steady state) and thus have to assume here that it is the monetary authority that enforces a certain steady state value for the nominal rate of interest.

Note 14. See Flaschel and Krolzig (2006), Chen and Flaschel (2006) and Proaño et al. (2006) for details.

Note 15. That may include - besides aggregate demand effects - aspects of supply side dynamics like substitution effects and more.

Note 16. Note here that also the cost - pressure parameters play a role here and may influence the critical stability condition that characterizes the real wage channel, see Flaschel and Krolzig (2006) for details.

Note 17 . We here assume that the growth rate of labor productivity $\hat{z}$ enters (as an exogenous variable) the wage equation with a coefficient that need not be unity and that wage cost pressure in the price Phillips curve of firms is reduced by the growth rate of labor productivity.

Note 18. Indeed, a GMM estimation, as stated in Wooldridge (2001, p.92), possesses several advantages with respect to more traditional estimation methods such as OLS and 2SLS, especially in time series models, where heteroskedasticity in the residuals is a common feature: "The optimal GMM estimator is asymptotically no less efficient than two-stage least squares under homoskedasticity, and GMM is generally better under heteroskedasticity." This and the additional robustness property of GMM which has the advantage of not relying on a specific assumption with respect to the distribution of the error terms make the GMM methodology appropriate and advantageous for our estimation.

Table 1. Four Baseline Real Wage Adjustment Scenarios

\begin{tabular}{|c|c|c|}
\hline labor market-led & $\left(\begin{array}{ll}- & + \\
+ & -\end{array}\right)$ & $\left(\begin{array}{ll}- & + \\
- & -\end{array}\right)$ \\
\hline real wage adjustment & - divergent or convergent - & - convergent - \\
\hline goods market-led & $\left(\begin{array}{ll}- & - \\
+ & -\end{array}\right)$ & $\left(\begin{array}{ll}- & - \\
- & -\end{array}\right)$ \\
\hline real wage adjustment & - convergent - & - divergent of convergent - \\
\hline
\end{tabular}


Table 2. U.S. Macroeconomic Time Series

\begin{tabular}{|c|c|}
\hline Variable & Description of the original series \\
\hline$e:$ & Employment Rate \\
\hline$u:$ & Output Gap \\
\hline$w:$ & Nonfarm Business Sector Compensation Per Hour (s.a.), 1992=100 \\
\hline$p:$ & Gross Domestic Product: Implicit Price Deflator (s.a.), 2000=100 \\
\hline$p_{c}:$ & Consumer Price Index for All Urban Consumers: All Items (s.a.), 1982-84=100 \\
\hline$z:$ & Nonfarm Business Sector Output Per Hour of All Persons (s.a.) 1992=100 \\
\hline$v:$ & Nonfarm Business Sector Unit Labor Cost deflated by the \\
\hline$i:$ & Nonfarm Business Sector Implicit Price Deflator (s.a.), 1992=100) \\
\hline Source: & Effective Federal Funds Rate \\
\hline
\end{tabular}

Table 3. U.S. GMM Parameter Estimates (std. errors in brackets)

\begin{tabular}{|c|c|c|c|c|c|c|c|c|}
\hline & & & stimation & ample: & $973: 1$ & -2008 & & \\
\hline & $1.5 \mathrm{ex}$ & ernel: Ba & ett, Band & idth: vari & able New & y-West ( & , no pr & ning \\
\hline & $\beta_{w e}$ & $\beta_{w v}$ & $\kappa_{w p}$ & $\beta_{w u} \chi$ & $u_{o}^{c} / e_{o}$ & $\kappa_{w z}$ & $\bar{R}^{2}$ & DW \\
\hline$\hat{w}_{t}$ & 0.277 & -0.125 & 0.486 & 0.668 & 1.048 & 0.245 & 0.561 & 1.974 \\
\hline & {$[0.072]$} & {$[0.036]$} & {$[0.092]$} & {$[0.112]$} & {$[0.004]$} & [0.079] & & \\
\hline & $\beta_{p u}$ & $\beta_{p v}$ & $\kappa_{p w}$ & & & & $\bar{R}^{2}$ & DW \\
\hline$\hat{p}_{t}$ & 0.105 & 0.034 & 0.289 & & & & 0.674 & 1.302 \\
\hline & {$[0.004]$} & {$[0.029]$} & {$[0.044]$} & & & & & \\
\hline$\hat{u}_{t}$ & $\beta_{u u}$ & $\beta_{u i}$ & $\beta_{u v}$ & & & & $\bar{R}^{2}$ & DW \\
\hline & -0.078 & -0.019 & -0.065 & & & & 0.889 & 1.470 \\
\hline & [0.012] & {$[0.007]$} & [0.014] & & & & & \\
\hline & $\beta_{e u} \chi$ & $u_{o}^{c} / e_{o}$ & & & & & $\bar{R}^{2}$ & DW \\
\hline$\&$ & 0.028 & 1.047 & & & & & 0.945 & 1.514 \\
\hline & [0.008] & {$[0.006]$} & & & & & & \\
\hline & $\varphi_{i i}$ & $\alpha_{i p}$ & $\alpha_{i u}$ & & & & $\bar{R}^{2}$ & DW \\
\hline$i$ & 0.907 & 1.59 & 1.029 & & & & 0.914 & 1.667 \\
\hline & {$[0.009]$} & {$[0.083]$} & {$[0.154]$} & & & & & \\
\hline & Deter & inant Res & dal Covar & ance & & & 3.371 & \\
\hline & & $\mathrm{J}-\mathrm{Sta}$ & & & & & 0.1 & \\
\hline
\end{tabular}




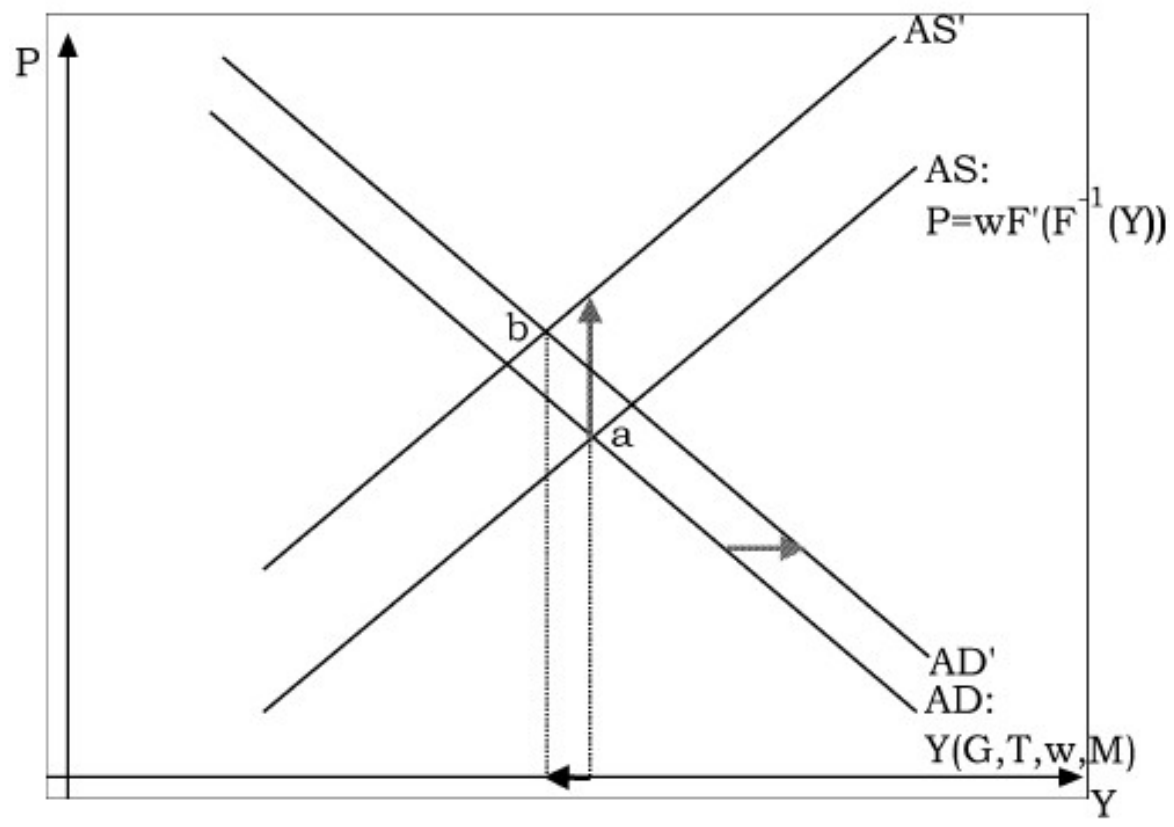

Figure 1. Wage led demand implies profit led activity in conventional Keynesian AS-AD analysis
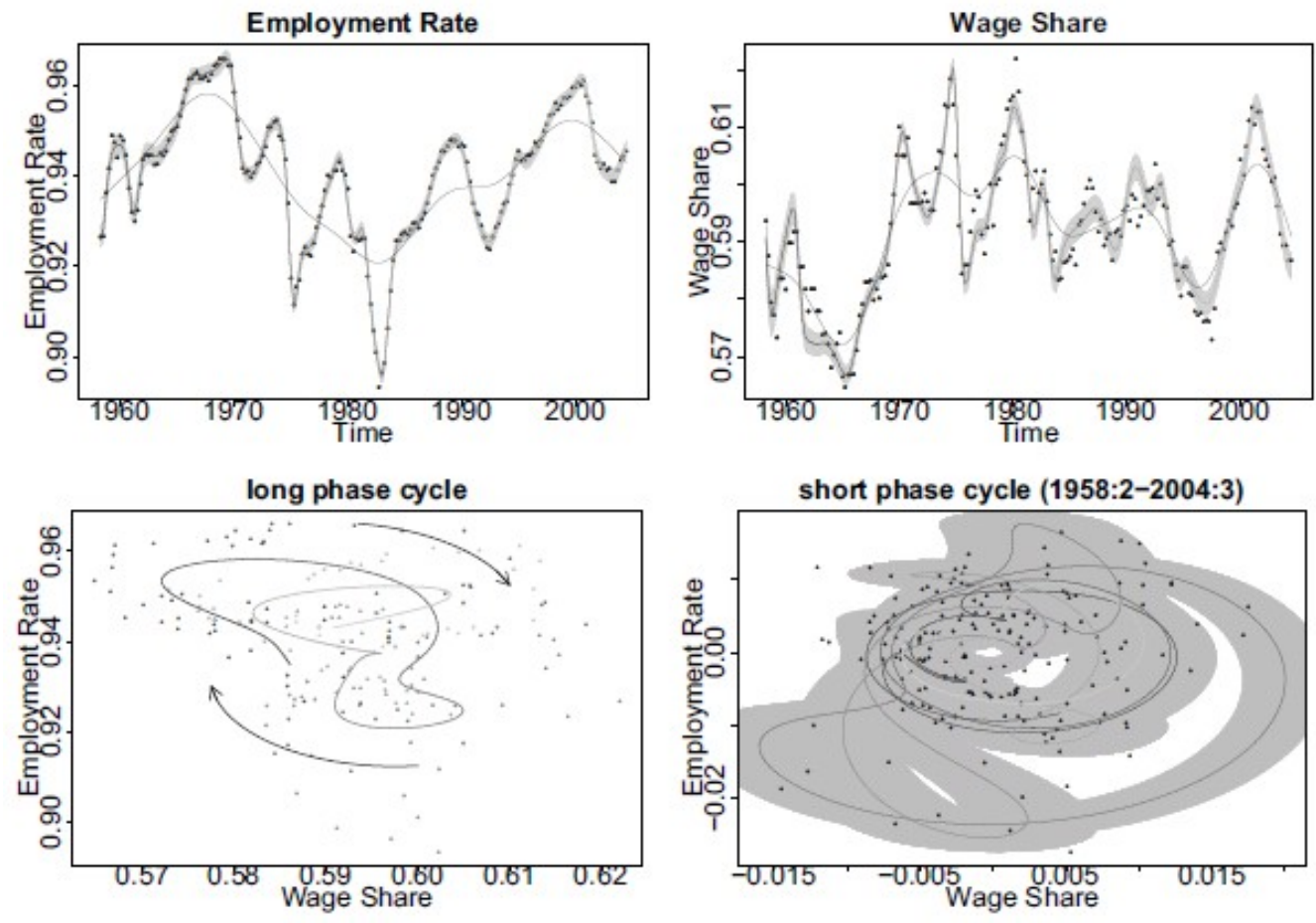

Figure 2. Short- and long cycles in the US distributive dynamics 

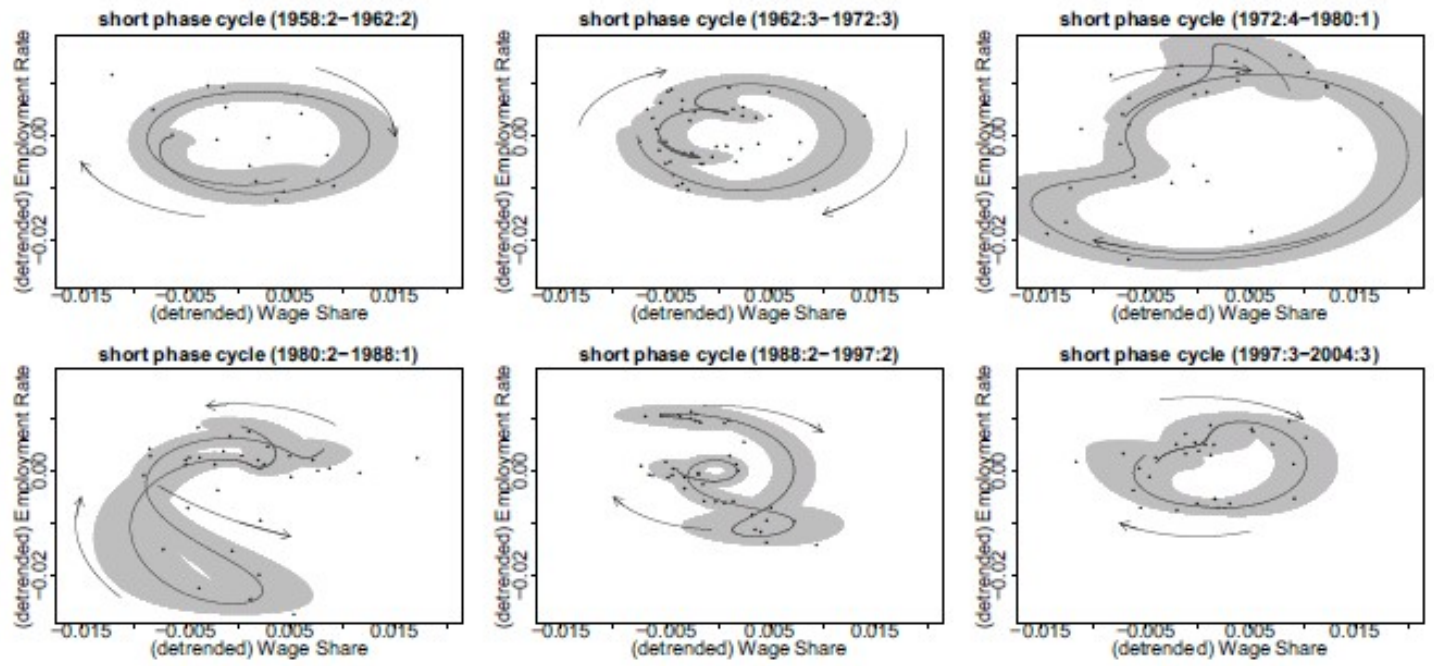

Figure 3. US distributive cycles of business cycle frequency

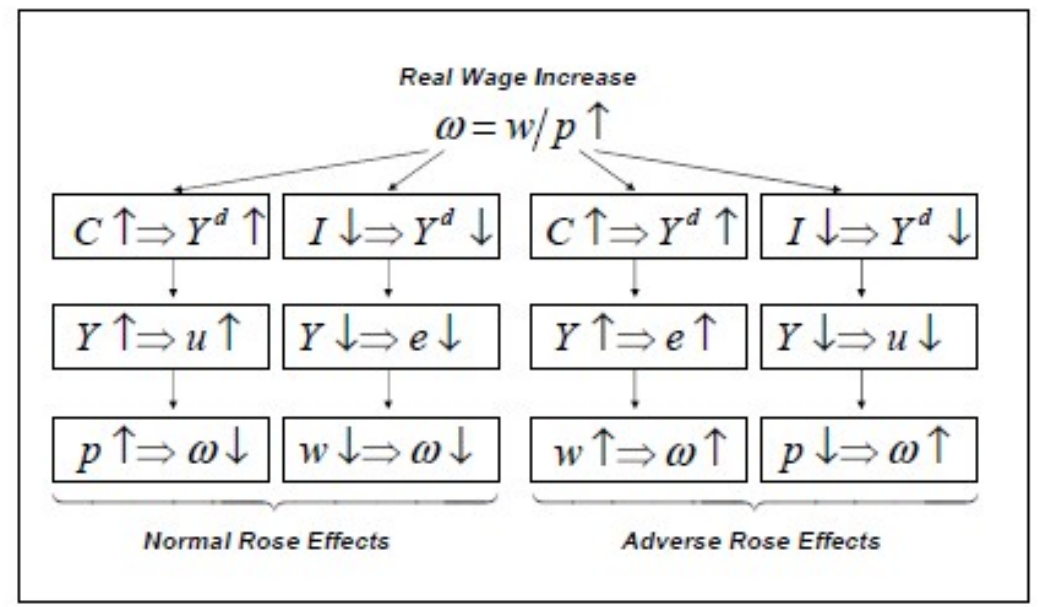

Figure 4. Normal (Convergent) and Adverse (Divergent) Rose Effects: The Real Wage Channel of Keynesian Macrodynamics 


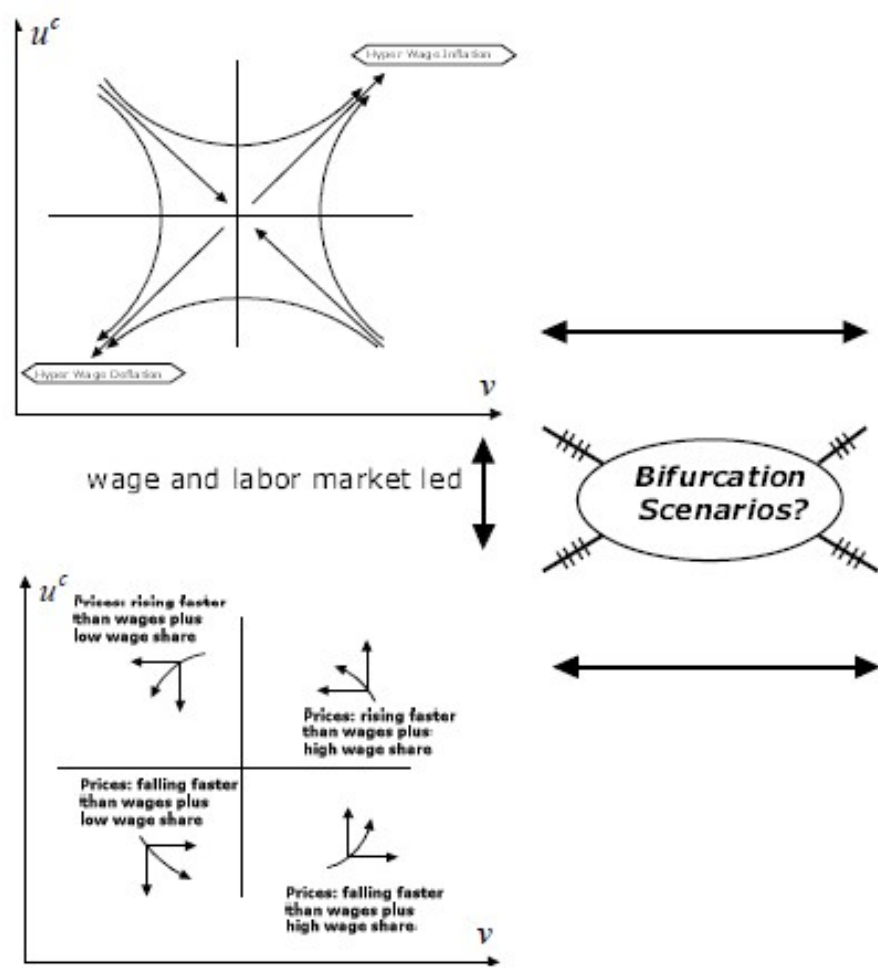

wage and goods market led

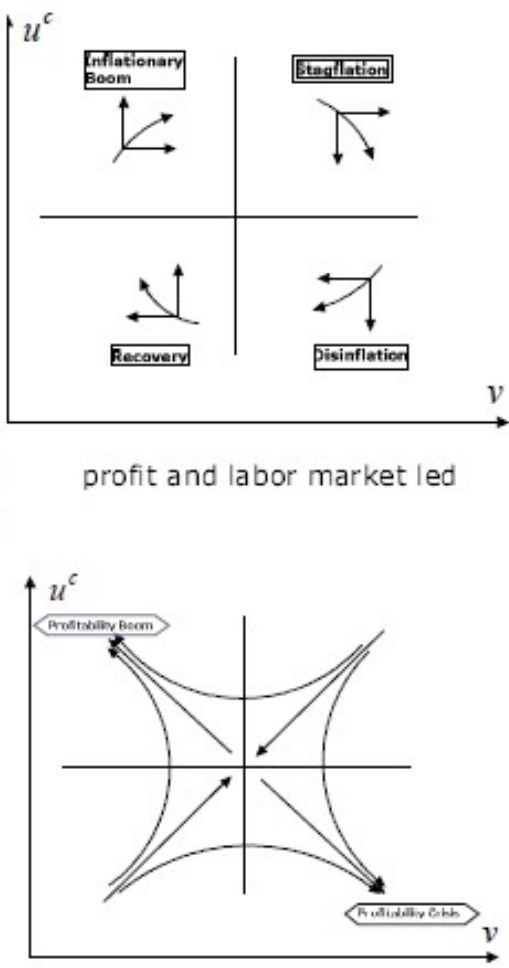

profit and goods market led

Figure 5. Phase portraits of the 4 types of Real Wage Channels of Keynesian macrodynamics 